\title{
Revolução burguesa e educação: uma relação necessária
}

Anita Helena Schlesener

Universidade Tuiutí do Paraná

\section{Resumo}

0 objetivo desse trabalho é analisar aspectos da implementação dos sistemas de ensino para esclarecer, basicamente, os conceitos de democracia e educação. Pretende-se salientar detalhes da revolução burguesa e como, para as classes populares, a relação entre formação política e formação cultural é fundamental para a experiência de uma democracia concreta. A luta de classes assume uma dimensão cultural na medida em que a hegemonia constitui-se como dominação e direção intelectual e moral. Essa leitura baseia-se no pensamento de Gramsci, que mostra como a educação laica e gratuita é um dos princípios básicos das democracias modernas.

Palavras-chave: Democracia. Formação política. Educação. 


\section{The burgeois revolution and education: a necessary relationship}

The aim of this paper is to analyze certain aspects of the implementation of teaching systems, in order to basically clarify the concepts of democracyand education. The intention is to point to certain details of the bourgeois revolution and to how, for the working classes, the relationship between political formation and intellectual formation is fundamental for the experience of a real democracy. Class conflict takes on a cultural dimension, as hegemony becomes established as the intellectual and moral domination and direction. This interpretation is based on Gramsci's thought, which demonstrates how secular and free education is a basic principle of modern democracies.

Keywords: Democracy. Political formation. Education.

\section{La revolución burguesa y la educación: una relación requerida}

El objetivo de este estudio es analizar los aspectos de los sistemas educativos de la revolución burguesa, básicamente para aclarar los conceptos de la democracia y la educación. Para las clases populares, la relación entre la educación y la formación política es fundamental para la experiencia cultural de una democracia real. La lucha de clases adquiere una dimensión cultural en la medida en que la hegemonía se constituye como dominación y dirección intelectual y moral. Esta lectura se basa en el pensamiento de Gramsci, que muestra cómo la educación laica y gratuita es un principio básico de las democracias modernas.

Palabras clave: Democracia. Formación política. Educación. 


\section{Introdução}

No âmbito da revolução burguesa, salientamos principalmente três momentos que marcaram o início da sociedade moderna: a revolução econômica inglesa, a revolução religiosa e filosófica alemã e a revolução política francesa: todos esses momentos foram acompanhados por mudanças estruturais no sistema escolar, o que evidencia a dimensão social e política da educação. Embora fossem revoluções distintas que, por sua vez, se compunham de outras "revoluções", todas rejeitavam as condições políticas postas pelo absolutismo e defendiam a instituição de uma nova soberania fundada na participação popular, ressalva feita à ambiguidade da ideia de povo.

A presente leitura visa explicitar a dimensão política da educação a partir das condições que se colocaram com as revoluções burguesas, nas várias formas que estas assumiram no contexto político europeu: a base teórico-metodológica de reflexão é buscada nos escritos de Gramsci que, ao acentuar a dimensão cultural da política, salientou a importância da educação para a construção de uma nova ordem social e política. A noção gramsciana de política amplia a noção implícita nos escritos de Marx e enraíza-se na tradição política moderna, na qual o poder se consolida como relação de domínio do indivíduo sobre o indivíduo e do indivíduo sobre a natureza. 0 interesse de Gramsci pela história francesa deve-se tanto ao tema da revolução quanto ao tema dos intelectuais, sempre analisados a partir das condições sociais e políticas de seu tempo. Desde os primeiros artigos de 1916 até os Cadernos do Cárcere, a política francesa é o pano de fundo para interpretar a história do século XX, desde o movimento do Risorgimento italiano até a Revolução de Outubro. A relação entre política e cultura expressa-se no fato de a Revolução Francesa ter sido sedimentada pelo pensamento de intelectuais profundamente envolvidos no movimento e que, a partir de sua atuação, deram a ele direção filosófica. Gramsci vincula ainda ao movimento iluminista a força renovadora e expansiva da Reforma Protestante enquanto movimento cultural que, no entender de Gramsci, foi comparável ao 'Iluminismo 'político' francês que precedeu e acompanhou a Revolução de 1789: também este foi uma reforma intelectual e moral do povo francês" (Gramsci, 1978, p. 423). ${ }^{1}$

Por outro lado, a leitura crítica da racionalização do processo de trabalho, resultado das transformações tecnológicas e organizativas do modo de produção na fase do americanismo e fordismo, feita por Gramsci nos permite fazer algumas observações sobre a modernidade tecnocrática, visto o modo como esse autor acentua a necessidade de mudança que essa racionalização determinou na formação do comportamento e de

1. Todas as citações de Gramsci aqui apresentadas são traduções minhas. 
um novo tipo humano adequado às exigências do processo produtivo (Gramsci, 1978). Essas novas exigências do sistema produtivo interferem no processo educativo e colocam novos objetivos na formação dos trabalhadores que, de modo indireto, também alteram o processo educativo escolar.

\section{As revoluções burguesas e a educação}

A revolução burguesa tem seu início no século XIII, época denominada por Agnes Heller (1982) "a aurora do capitalismo", que culminou no Renascimento; esse termo designa um processo social amplo, que abarca tanto a esfera econômica e social quanto o domínio da cultura, colocando as bases da revolução científica moderna e estendendose à vida e aos modos de pensar cotidianos, às práticas morais, aos ideais éticos, estéticos e políticos. Um tempo de transição, em que as antigas formas econômicas e sociais ainda não se haviam dissolvido e as novas formas já se encontravam em formação.

Um período que abre a senda para movimentos posteriores, como a Revolução Industrial ocorrida mais tarde na Inglaterra, a qual se constituiu de vários movimentos contestatórios que propunham ações políticas renovadoras; o movimento inglês foi acompanhado por uma corrente política liberal que contribuiu para elaborar a idéia de povo soberano, sustentação das normas institucionais que se tornaram uma das bases da democracia moderna, principalmente com a teoria constitucionalista que se legitimava na representatividade de indivíduos eleitos pelo povo.

No final do século XVII, a reflexão política de Locke, apresentada nos Dois Tratados sobre o Governo Civil, distinguia os poderes paterno, despótico e político ou civil esclarecendo seus fundamentos: o poder dos pais era resultante de uma condição natural pela qual se estabeleciam os direitos e deveres de geração, os pais exerciam autoridade e tinham a obrigação de proteger (alimentar e educar) os filhos até que atingissem o uso da razão e pudessem reger-se pelas leis (naturais ou civis); o poder despótico era o poder absoluto que uma pessoa tinha sobre outra a partir do castigo por um delito que ferisse as leis naturais e subordinasse o ofensor ao ofendido; o poder político se diferenciava dos dois primeiros por nascer do consentimento, de um acordo voluntário que legitimava a nova autoridade e a atuação dos governantes, a fim de legislar em benefício comum. Locke, ao lado de Hobbes, Spinoza, Rousseau e outros intelectuais da época, muitos deles teóricos do direito natural, foram os que elaboraram os princípios do pensamento político moderno. Embora abordando a questão a partir de perspectivas diferentes, esses intelectuais afirmavam basicamente que tanto o Estado quanto a sociedade civil se organizaram a partir de pactos ou contratos firmados entre os 
indivíduos para regulamentar o convívio social, superar as tensões e conflitos e instaurar a ordem política.

A revolução inglesa foi também uma revolução religiosa precedida por movimentos que já vinham acontecendo desde 1570: a Reforma Protestante questionou o poder concentrado na Igreja Católica pela unificação da interpretação da Bíblia escrita em latim. Ao traduzir o livro sagrado para o alemão, Lutero pretendia ampliar a possibilidade de interpretação; para isso, era necessário que os indivíduos soubessem ler. Portanto, junto com a Reforma, aconteceu uma ampliação do sistema escolar e uma abertura de acesso para as classes populares.

A filosofia alemã, também ela sustentação teórica desse movimento, teve no pensamento kantiano a sua principal expressão e colocou as bases conceituais necessárias para a formação da democracia burguesa; entre esses conceitos, destaca-se a ideia de indivíduo autônomo capaz de se desvencilhar de todas as tutelas e decidir o seu destino por sua própria cabeça. Deu-se ainda uma revolução filosófica que também questionou a religião, ao argumentar sobre a impossibilidade de se demonstrar a existência de Deus.

Para Heine, esta radicalidade restringiu-se aos intelectuais: os efeitos destruidores do pensamento de Kant sobre a metafísica e sobre a ideia de Deus na Crítica da Razão Pura, que Heine denomina "a espada com que se executou o deísmo na Alemanha" (Heine, 1991, p. 87), foram amenizados na Crítica da Razão Prática, onde Kant reabilitou o que havia demolido. A ironia de Heine acentuou as diferenças entre a situação alemã e a realidade da França, principalmente no fato de que os metódicos alemães só conseguiram partir para a ação política revolucionária um século depois dos franceses, apesar da crítica radical à religião. Diz o autor: "confesso sinceramente que vocês, franceses, são moderados e dóceis em relação a nós, alemães. Puderam no máximo matar um rei que já havia perdido a cabeça antes que vocês o decapitassem" (Heine, 1991, p. 89). Para Heine, Kant foi muito além de Robespierre, mas tinha com este algumas semelhanças:

Em ambos encontramos a mesma inexorável, cortante, apoética e insípida probridade. [...] o mesmo talento da desconfiança, ainda que um o exerça contra pensamentos e o chame de crítica, enquanto o outro o emprega contra seres humanos e the dá o título de virtude republicana. Em ambos, porém, o tipo provinciano é aquilo que se destaca em seu mais alto grau - a natureza os destinou a pesar café e açúcar, mas quis a sina que ponderassem outras coisas e pôs para um, um rei e, para outro, um Deus no prato da balança... (Heine, 1991, p. 90)

Kant "tomou o céu de assalto" e "destruiu os fundamentos de prova da existência de Deus" (Heine, 1991, p. 97). Contudo, a crítica kantiana permaneceu abstrata, visto que a sua reflexão filosófica, em seu segundo momento, reabilitou a ideia de Deus, com 
uma função ideológica clara para Heine, que era a de criar as condições para que os comuns mortais como o velho Lampe, criado de Kant, fossem felizes. Heine revela aqui como a mistificação das massas começa a se enunciar a partir do discurso filosófico. 0 questionamento de antigos dogmatismos tem uma função educativa que visa legitimar os interesses revolucionários da burguesia naquele momento histórico, sem contudo desestabilizar as crenças populares.

A revolução filosófica iniciada por Kant completou seu ciclo com Hegel. A partir de Marx, a filosofia alemã redefiniu suas bases de interpretação do real e abriu a perspectiva de uma revolução política na Alemanha, com a fusão da teoria à realidade social e histórica. 0 conhecimento apresenta-se como produzido no interior de um movimento que unifica ação e pensamento, movimento real que se oculta nas dobras do modo de produção e que se desvela nos momentos revolucionários.

Esse movimento se evidencia na Revolução Francesa, que aboliu as antigas formas de autoridade centralizada no nascimento e instituiu um novo Estado, cujo poder deveria ser construído com base na autonomia de um cidadão livre e esclarecido. 0 pensamento iluminista reforçou e ampliou o papel da racionalidade ao acentuar que a razão se constituía no corolário da vida política, cujo fundamento era a liberdade de pensamento e expressão. Como acentuou Gramsci, "cada revolução foi precedida por um intenso trabalho de crítica, de penetração cultural, de permeabilização de ideias" (Gramsci, 1976, p. 83), ou seja, a grande crise política que se estendeu pela Europa a partir do século XV teve aspectos econômicos, políticos, religiosos e filosóficos os quais, na sua interação, possibilitaram lançar as bases da democracia moderna. Como acentua Saviani, “toda postura revolucionária é uma postura essencialmente histórica, é uma postura que se coloca na direção do desenvolvimento da história” (Saviani, 2008, p. 32), ou seja, da superação das contradições postas pelo conjunto das relações econômicas, sociais e políticas.

As promessas de autonomia que fundavam o movimento revolucionário exigiam a ampliação do sistema escolar e do acesso ao saber, promessas liberais que se modificaram no curso da história, mediadas pelas condições materiais objetivas dadas no desenvolvimento do processo de produção; os interesses econômicos delinearam os objetivos políticos da burguesia, que demonstrou sua força conservadora e reacionária na mesma medida em que as classes populares reivindicavam seus direitos de participação. Uma correlação de forças que tornou a representação um dos elementos fundamentais das democracias modernas, e a ideologia uma de suas sustentações mais eficazes. Nesse movimento de produção das novas relações políticas, as democracias modernas propunham-se garantir educação laica e gratuita a todos como base para a efetiva consolidação da cidadania. 
Na prática, esses princípios assumem contornos diversos à medida que a desigualdade social é produzida no modo de produção capitalista e que os interesses das classes economicamente dominantes prevalecem; a igualdade enquanto base de sustentação da política revela-se irreal e as afirmações do pensamento liberal, que se concretizam no Estado burguês, assumem um significado mistificador junto às classes populares e subalternas. A igualdade que sustenta a representação política é, na realidade, uma utopia que não se realiza, mas alimenta o imaginário social. A crença comum de que o número (de votantes) seria a expressão da vontade comum, que se traduziria na quantidade como garantia da qualidade e da igualdade de representação, não se efetiva porque a igualdade política sustenta-se na desigualdade econômica; no curso das democracias modernas, o voto tem se transformado em mero simbolismo legitimador da ação de políticos que agem em nome de interesses individuais ou de grupos. Do ponto de vista da educação, a garantia de uma escola laica e gratuita torna-se um princípio legal que não garante a igualdade de acesso ao saber historicamente produzido.

0 pensamento liberal, separando política de economia, criou uma prática que também oculta a lógica imanente ao contexto econômico e social: a realidade são as condições materiais objetivas que se expressam na desigualdade econômica e social; a forma encontra expressão no direito, que concretiza as relações de dominação ao pressupor que todos são iguais e livres quando, na verdade, a estrutura econômica determina os limites de igualdade e liberdade. Somente o processo de formação de uma consciência política por parte das classes populares, por meio da organização política e da educação, pode permitir a alteração da correlação de forças que constitui as relações de poder em determinado momento histórico.

Nesse contexto, a educação assume um significado amplo e se enraíza na política e, na sociedade capitalista, é entendida como um processo pelo qual o indivíduo se adapta às necessidades e exigências do modo de produção e é formado para desempenhar funções na hierarquia que separa dirigentes de dirigidos; essa definição baseia-se nos escritos de Gramsci, que acentuam a necessidade da organização política de trabalhadores e trabalhadoras no contexto em que a educação teria que assegurar o desenvolvimento integral da personalidade individual a partir do processo de construção de novas relações de formação coletiva.

No âmbito das relações políticas nascidas no processo de revolução burguesa, a expansão dos sistemas de ensino que, em origem, ampliavam o acesso ao conhecimento historicamente produzido também vai se constituindo, no curso da história, em formadores para as mudanças no sistema econômico, para a adaptação dos(as) trabalhadores(as) às mudanças geradas pela aplicação de novas tecnologias ao modo de produção. Com o desenvolvimento tecnológico dos meios de comunicação, aliado ao surgimento de 
grandes centros urbanos com concentração de grandes massas, a educação escolar passou a ter como seu contraponto essas outras instâncias de formação. Os meios de comunicação de massa assumiram a tarefa de formar a maneira de imaginar e entender o mundo, tratando os conflitos sociais, inerentes a uma sociedade fundada na desigualdade econômica e social, de modo estático e dualista: noções preconcebidas de bem e de mal permeiam um discurso que não dá margens a dúvidas e questionamentos; não só a produção cultural é simplificada e nivelada para responder aos objetivos do consumo, mas o mundo é desfigurado a partir de novos fundamentos instrumentais da política.

Já nos anos da Restauração francesa, as classes dominantes empreenderam atividades visando o monopólio das comunicações num processo que, conforme Losurdo, "exclui diretamente as massas populares do exercício dos direitos políticos" (Losurdo, 2004, p. 149). Essa busca das classes dominantes pelo controle efetivo dos meios de comunicação de massa se acentua no início do século XX, precisamente na fase de luta das classes trabalhadoras por efetivação de direitos sociais. Mesmo com o retorno de políticas republicanas que fizeram cair o controle direto e a censura, a instituição de uma garantia monetária para possuir um meio de comunicação, por exemplo, tornou-se uma prática excludente importante para a formação ideológica das massas populares.

O século XX viveu uma expansão dos meios de comunicação de massa e uma ampliação inusitada dos mecanismos de manipulação política, acentuando o uso da ideologia como prática de poder. Gramsci (1978), já na década de 30, acentuava o uso dos jornais para a formação da opinião pública e seu direcionamento para um ou outro lado no momento da eleição, bem como a necessidade de uma formação política e cultural realizada pelas próprias classes trabalhadoras a partir de suas instituições organizativas. 0 trabalhador "deve negar decididamente qualquer solidariedade com o jornal burguês. Deveria recordar-se sempre, sempre, sempre, que o jornal burguês (qualquer que seja a sua cor) é um instrumento de luta movido por idéias e interesses que estão em contraste com os seus" (Gramsci, 1975, p. 53). Essas questões, ampliadas no final do século, limitaram a própria atuação da escola enquanto formadora de uma consciência crítica.

Embora os limites sejam claros, cabe acentuar que é nesse contexto que são geradas as condições para o exercício do pensamento e, com ele, a possibilidade de expressão e de emancipação política das classes populares e, embora de modo restrito, a escola ainda oferece as condições de formação crítica como caminho para socializar a política e efetivar relações democráticas. Nesse contexto, assim como o era na Reforma Protestante, a educação continua sendo de fundamental importância para as 
massas populares; a concretização da liberdade no âmbito dessa sociedade depende da mudança dos costumes e da possibilidade de acesso ao saber historicamente construído, a fim de elaborar um novo modo de pensar crítico. No âmbito da organização política dos trabalhadores, a necessidade de defender uma escola livre e inovadora como meio de conquista da liberdade política para todos é fundamental, visto que, como acentua Gramsci, a emancipação política das classes populares pressupõe compreender os limites da própria concepção de mundo a fim de torná-la coerente e autônoma no movimento de "elevá-la ao ponto alcançado pelo pensamento mundial mais desenvolvido" (Gramsci, 1978, p. 1376).

\section{A importância da educação para as classes populares}

O breve histórico do nascimento das democracias modernas visa acentuar tanto a significação das novas relações políticas para a ampliação dos sistemas de ensino quanto a importância da educação para as classes populares. Embora se tenha consciência dos limites do sistema escolar, a escola tem uma significação importante para as classes populares na formação para o trabalho e para o acesso ao conhecimento historicamente produzido.

A partir dos escritos de Gramsci (1978) pode-se dizer que é nesse contexto que a educação assume uma dimensão política: conforme a natureza do Estado e os interesses econômicos que se evidenciam, elaboram-se as políticas públicas que definem o encaminhamento do processo de educação escolar; a compreensão das relações de poder que se instauram entre classes sociais antagônicas e da correlação de forças que entre elas se instauram no curso do processo político visando a conservar ou a conquistar a hegemonia é de fundamental importância para a formação de uma concepção crítica da realidade; a escola assume uma significação importante nesse processo, em qualquer realidade social e política. Para Gramsci, as classes trabalhadoras precisam criar outras instituições educativas que ampliem o que lhes apresenta a escola, a fim de elaborar uma nova concepção de mundo que expresse a dimensão política de suas lutas.

As possibilidades de participação política que se instauram com a democracia moderna exigem também que o acesso ao conhecimento se produza como um processo de construção da liberdade. Para conquistar a liberdade ou liberar o pensamento de seus condicionamentos ideológicos em momentos nos quais a disparidade econômica, a propaganda e a mistificação ideológica podem condicionar a formação de opinião e direcionar a escolha política, a formação crítica é uma tarefa fundamental, em grande parte atribuída à escola. Embora de modo limitado, a escola abre a possibilidade de 
conhecer e defender direitos civis e políticos a partir do modo como pode formar a consciência crítica.

A cada momento histórico, conforme a correlação de forças políticas, a educação assume características específicas e a atuação da escola se reconfigura. Desse modo, no processo revolucionário burguês, a vigência de novas relações políticas criou as condições para a implantação e a ampliação dos sistemas de instrução: assim como a Reforma Protestante exigiu a ampliação do sistema escolar para proporcionar às classes populares o acesso ao conteúdo da Bíblia recém traduzida, as novas idéias de legitimidade do poder e de soberania, enraizadas na secularização da autoridade política e da razão como princípio de autonomia e liberdade, exigiram uma ampliação do acesso ao saber a todos e todas os cidadãos(ãs).

A valorização da instrução já se pode rastrear no Renascimento: Florença e Veneza, os grandes centros políticos da época, apresentavam a preocupação com a alfabetização e a formação para a vida social; além da escrita e da leitura básicas, jovens recebiam conhecimentos de aritmética e contabilidade para as transações comerciais; um menor número alcançava as universidades, onde aprendia o necessário para o exercício do direito e para outras profissões liberais que exigiam o latim, a lógica e a retórica. Existiam ainda escolas-oficinas, nas quais os jovens burgueses, sob a orientação de um artesão ou artista, praticavam muitas atividades: pintura, escultura e obras de engenharia, até a elaboração e reparo de objetos em ferro, a fabricação de objetos artesanais de madeira, desde móveis em geral até aberturas, como portas e janelas. Para Heller, a democracia, "surgindo a um nível relativamente alto da cultura técnica, constituía a condição prévia e o fundamento de uma cultura geral modelar e universal" (Heller, 1982, p. 13).

No curso dos séculos, o processo de instituição dos novos Estados aumentou a preocupação com a educação: os políticos convenciam-se de que a liberdade política exigia que o povo alcançasse certo grau de instrução e passavam a defender a escola para todos. Os primeiros projetos de lei já aparecem no primeiro período da Revolução Francesa com base nas teorias dos enciclopedistas e também na Revolução Americana, a partir de discursos em defesa dos direitos naturais tendo como base principalmente a teoria de Locke e de Franklin.

Da perspectiva cultural, a Reforma Protestante coloca a necessidade de educação para as classes populares, formação que vem acompanhada do debate de questões sociais concretas por parte dos reformadores. As cidades que aderiam ao movimento empenhavam-se em instituir escolas comunais gratuitas, que se dedicavam tanto a instruir quanto a preparar para uma atividade. A instrução estendia-se tanto ao meninos quanto as meninas que, como futuras mães, deveriam ter condições de preparar os 
filhos para uma conduta honrada. Além da formação moral, os reformadores salientavam o respeito pelo trabalho, tanto manual produtivo quanto intelectual. Embora as divisões sociais não sejam superadas e nem se proponha a sua superação, “as classes destinadas a produção são consideradas não mais como os principais destinatários da catequese cristã, mas também como participantes ativos no processo comum da instrução", colocando-se o problema da instrução-trabalho. A exigência da cultura popular vincula-se ao desenvolvimento das capacidades produtivas e ao processo de participação das massas na vida política (Manacorda, 1989, p. 198).

Se a Reforma Protestante motivou a expansão do sistema educativo pelo norte da Europa, a Igreja Católica empenhou-se, a partir da Contra-Reforma e nos séculos seguintes, a consolidar um sistema educacional capaz de dar uma formação ideológica consistente não apenas para confrontar-se com o movimento reformista, mas para reforçar o seu poder cultural na sociedade civil.

As reformas e ampliações da educação escolar tornaram-se tema das políticas públicas nas democracias modernas; as novas propostas pedagógicas, a instituição do ensino laico, a reformulação da disciplina com diminuição de punições aos alunos foram alguns motivos de resistência da Igreja Católica que, ao longo dos séculos, procurou ampliar a sua organização educacional; e a correlação de forças do clero com a burguesia assumiu formas diversas nos novos Estados.

Na Itália, centro da Contra-Reforma, o empenho da Igreja Católica na concentração de sistemas de ensino e na produção editorial pode ser evidenciado no curso da história. A Igreja se beneficia política e culturalmente das fraquezas e do conservadorismo da burguesia que, conforme Gramsci (1978, Q 8 e 12), afirma fragorosamente seu laicismo, mas termina por ceder aos interesses da Igreja tanto na instauração de escolas religiosas quanto no ensino da religião nas escolas públicas (Gramsci, 1982, p. 339-341). Também na França a Igreja Católica conseguiu influenciar a educação nos períodos de restauração, com características específicas a cada época, mas sempre procurando consolidar sua influência ideológica e cultural.

Por outro lado, a cada novo momento histórico a correlação de forças entre tendências da burguesia reflete-se na proposição de políticas públicas para a educação, o que recompõe constantemente o ideal educativo e pedagógico e as propostas de ampliação estrutural do sistema escolar. Desse modo, a escola orienta-se por políticas que, muitas vezes, reforçam a técnica e a formação profissional, outras vezes incentivam a alfabetização e a cultura geral, mas sempre delimitada por interesses sociais específicos, de acordo com a divisão social e interesses de classe.

Se nos momentos revolucionários a expansão da educação popular assume uma característica crítica, nos períodos de restauração as políticas públicas que regem o 
sistema escolar retomam aspectos tradicionais e restringem as possibilidades de formação crítica. É o que se deduz, por exemplo, comparando o período francês de 1789-1792 e o período Napoleônico; ou analisando as reformas educacionais no curso da história do Estado moderno: as políticas públicas evidenciam a primazia dos interesses burgueses, ora no incentivo à formação clássica, ora no investimento na formação profissional ou nas duas ao mesmo tempo, concretizando a formação diferenciada de classe.

Esse longo processo que abriu o acesso das massas populares à educação básica também instaurou uma grande distância entre a teoria e a prática política: o sufrágio, embora denominado universal, era inicialmente privilégio apenas dos homens proprietários; o acesso amplo à participação política foi uma árdua conquista dos trabalhadores e das mulheres, movimentos que em alguns momentos se organizaram concomitantemente. Um exemplo foi Clara Zetkin que, na Alemanha de 1914, foi militante do Partido Social-Democrata Alemão e organizadora do movimento feminista, embora nem sempre os companheiros da social-democracia apoiassem resolutamente o movimento das mulheres (Badia, 2003, p. 107).

Quanto à escola, as classes trabalhadoras também tiveram que lutar por seus direitos e, em momentos revolucionários, criar suas próprias instituições de educação; nas escolas públicas, a alfabetização inicial, sem a disciplina e a continuidade, perdese no esquecimento; a formação para o trabalho sem a base da cultura geral limita a formação política. Na organização política as classes trabalhadoras também reivindicam a possibilidade de acesso a uma formação integral, base para qualquer transformação social e política.

\section{A modernidade tecnocrática}

Ao lado das lutas por direitos, foi o princípio igualitário, pilar do sufrágio universal, que abriu a senda para a defesa da obrigatoriedade da educação escolar, seguida pela gratuidade da instrução pública, como direitos sociais que deveriam ser garantidos pelo Estado. Conforme Gramsci, o que importa aos trabalhadores é pensar "concretamente, transformar, homogeneizar" seu movimento conforme o "processo de desenvolvimento orgânico que eleve do simples senso comum ao pensamento coerente e sistemático" (Gramsci, 1978, p. 2264), que se elabora ao longo da vida e da organização política dos trabalhadores. Essa sistematização, a escola, independentemente do conteúdo que apresenta, consegue oferecer.

Em linhas gerais, a modernização vem exigindo que as instituições escolares possibilitem um "conhecimento mais acabado, preciso e 'objetivo' da realidade", visto 
que "a ciência e sua aplicação técnica" tornaram-se "uma força produtiva decisiva para o ciclo produtivo do sistema" (Gruner, 2007, p. 106). A cada nova inserção de tecnologia modificam-se as relações internas do processo produtivo e os trabalhadores precisam adaptar-se às novas exigências colocadas, num movimento doloroso de aprendizagem que modifica hábitos e costumes. Do ponto de vista do materialismo histórico, conhecer implica reconhecer as contradições produzidas no movimento do real; ater-se à aparência dos fatos, ao seu exterior ou ao seu resultado descritivo sem perceber o processo de construção do conhecimento caracteriza a alienação; no dizer de Kofler, "a falsa crença na possibilidade de aproximar-se" ao verdadeiro significado dos fenômenos “mediante a mera 'elaboração' formal de uma conexão" (Kofler, 2010, p. 92).

No curso da história moderna, formou-se e se consolidou a ideia de indivíduo isolado, sem um envolvimento preciso com a comunidade e, portanto, também sem compromissos políticos precisos. A técnica, separada do processo de produção do conhecimento, ou seja, apresentada como simples mecanismo instrumental, assumiu uma característica de neutralidade política. Essas condições, aplicadas ao modo de produção, geraram um grande desenvolvimento das forças produtivas, mas também transformaram todo o processo de conhecimento no âmbito do qual a fragmentação tornou-se um mecanismo de reforço das formas políticas de domínio. A informação fragmentada não permite a compreensão do processo de construção do saber e nem a visão de conjunto da relação teoria e prática, condições para um pensamento autônomo e crítico. A cisão epistemológica entre sujeito que conhece e objeto a ser conhecido desdobra-se na separação entre as várias instâncias que formam a vida do indivíduo, que não consegue identificar o movimento entre o social, o político e o cultural, nem o significado da formação histórica que possibilitou essa cisão.

Sem aprofundar aqui as consequências dessa concepção de conhecimento, fundamental para o desenvolvimento das forças produtivas e para a dominação da natureza e da humanidade no modo de produção capitalista, salientamos as mudanças que a inserção tecnológica acarretou na formação dos indivíduos e da organização política de classe. A partir das observações de Finelli (2003), Gramsci intuiu, fundamentado em suas reflexões sobre o americanismo do início do século XX, a difusão da racionalização do processo de trabalho no interior da totalidade social alterando as formas de sentir e de pensar. A exploração do trabalho assume novas proporções à medida que se consolidam os padrões de comportamento constantemente reafirmados pelos meios de comunicação de massa. 0 fato de a razão perder a sua característica principal de construir a relação entre particular e universal produz consequências também na formação dos trabalhadores e em toda a proposição de conteúdos no sistema escolar. 0 desafio da educação consiste em buscar os meios de superar a perda da capacidade 
de compreender o real em sua totalidade, a fim de retomar a capacidade de realizar experiências formativas.

Para Gramsci, preservando-se as diferenças, a compreensão desse movimento mistificador pelas classes populares pode eclodir apenas em momentos de crise econômica e política ou nos momentos de crise da hegemonia, quando a capacidade de organização política emerge e a história pode ser redefinida. 0 sistema escolar como um todo pode contribuir para a formação política das classes populares, mas em termos limitados, visto a sua função de adequar ou inserir no modelo social vigente. Em qualquer circunstância, as possibilidades educativas resultam das condições políticas e do modo como se organizam os movimentos sociais.

\section{Política e educação: retomando uma relação necessária.}

A política liberal é descrita por Gramsci como "ideia-limite" que criou "o Estado ético, um Estado que idealmente está acima das competições de classe", isto é, que se apresenta acima dos grupos sociais; na verdade, esses grupos "são a sua realidade econômica e tradicional", e esse ideário funciona como uma utopia democrática que é também a força do liberalismo, "a miragem que o torna robusto e o transforma em uma força de conservação" (Gramsci, 1975, p. 75).

Esse ideário sustenta que todos podem participar em condições de igualdade no processo político, com as mesmas chances de se tornarem dirigentes. 0 que Gramsci procura mostrar é que a política, no contexto da sociedade moderna, consolida-se sobre um discurso falso, que atua como invólucro e simulacro de uma realidade social cuja característica real é a desigualdade. Esses elementos podem ser reforçados a partir da consideração da cultura como um elemento fundamental da estrutura social e política, tanto que as transformações no processo produtivo sempre vêm acompanhadas de ajustes morais e da exigência de mudança no comportamento das classes trabalhadoras, mais atingidas pelas novas orientações na organização do trabalho. A Reforma protestante era reconhecida por Gramsci como um movimento que lançou as bases de uma ampliação do sistema escolar principalmente por entender a necessidade de formar a "consciência individual" assim como a "atividade criadora da história", fato que tornou o indivíduo "independente de toda autoridade, de todo Silabo" (Gramsci, 1975, p. 15).

Ora, os sistemas escolares apresentam-se como a oportunidade de aprender a viver as relações sociais e, ao mesmo tempo, a questioná-las. Se a sociedade moderna, nascida de várias revoluções, supõe e cria as condições para a expansão do sistema educativo, abre também a senda para a formação crítica do indivíduo e a organização dos grupos sociais para reivindicar uma efetiva participação política. 
Para cumprir essa função crítica cabe à escola retomar sempre a relação entre política e educação, a fim de compreender os limites de sua ação e esclarecer os mecanismos de funcionamento da estrutura social. A tarefa crítica da escola implica a compreensão de sua inserção no contexto das relações políticas: o modo como se elaboram as políticas públicas e quais os interesses que estas representam. Somente explicitando o significado da estrutura escolar no contexto social e político é que a escola poderá educar para a vida social e para a renovação das relações políticas, formando indivíduos capazes de entender o conjunto das determinações das quais participam para interferir na sua transformação.

Para isso, as propostas pedagógicas precisam ir além da simples resposta aos interesses de mercado e entender que as reformas de ensino não são simples reformas administrativas, mas supõem uma visão abrangente das relações sociais e dos interesses implícitos que, se não os conhecemos, acabamos sempre por referendar. Conforme Saviani, “a importância política da educação está condicionada a garantia de que a especificidade da prática educativa não seja dissolvida” (Saviani, 1984, p. 65).

Se entendermos que educar é formar para a vida em sociedade, é realizar uma idéia de civilização e se, retomando Gramsci, entendermos que essa função cabe ao Estado, é necessário explicitar a sua estrutura e conhecer os mecanismos dos quais lança mão para "criar e manter certo tipo de civilização" (Gramsci, 1978, p. 1570), isto é, quais interesses alimentam as políticas públicas e determinam a configuração da estrutura escolar e das propostas pedagógicas, a fim de gerar e consolidar uma determinada forma de convivência social e de relações individuais (Gramsci, 1978).

Portanto, entender a natureza do Estado e das relações de poder que se instauram entre classes sociais antagônicas é de fundamental importância para fazer da escola um dos centros de formação crítica, ao lado de outros mecanismos capazes de formar opinião e de gerar as condições de compreensão da atual realidade social e política. É por isso que a dimensão política da educação precisa ser explicitada como uma relação necessária.

\section{Referências}

BADIA, Gilbert. Clara Zetkin: vida e obra. [S.l.]: Expressão Popular, 2003.

FINELLI, Roberto. 0 "pós-moderno": verdade do "moderno". In: COUTINHO, Carlos Nelson; TEIXEIRA, A. De Paula. Ler Gramsci, entender a realidade. Rio de Janeiro: Civilização Brasileira, 2003. p. 99-112. GRAMSCI, Antonio. Escritos políticos. Lisboa: Seara Nova, 1976. 4 v. . La Città Futura (1917-1918). Torino: Einaudi, 1982. . Il nostro Marx (1918-1919). Torino: Einaudi, 1985. . Scritti Giovanili (1914-1918). Torino: Einaudi, 1975. 
Quaderni del Carcere. Torino: Einaudi, 1978.

GRUNER, Eduardo. Leituras culpadas: Marx(ismos) e a praxis do conhecimento. In: BARON, Atilio, AMADEO, Javier; GONZALES, Sabrina (Org.). A teoria Marxista hoje: problemas e perspectivas. São Paulo: Expressão Popular, 2007.

HEINE, Heirich. Contribuição à História da Religião e Filosofia na Alemanha. São Paulo: Iluminuras, 1991. HELLER, Agnes. O homem do Renascimento. Lisboa: Presença, 1982.

KOFLER, Leo. História e dialética: estudos sobre a metodologia da dialética marxista. Rio de Janeiro: Editora da UFRJ, 2010.

LOSURDO, Domenico. Democracia ou bonapartismo. Rio de Janeiro/São Paulo: UFRJ/UNESP, 2004. MANACORDA, Mario Alighiero. História da Educação: da Antiguidade aos nossos dias. São Paulo/ Campinas: Cortez Ed. /Autores Associados, 1989.

SAVIANI, Dermeval. Escola e democracia. Campinas: Autores Associados, 2008.

$1{ }^{\text {a }}$ versão recebida em novembro de 2010

$2^{\text {a }}$ versão aprovada em maio de 2011

Anita Helena Schlesener possui doutorado em História e é professora (aposentada) de Filosofia Política e Estética da UFPR. Atualmente é Professora do Mestrado e Doutorado em Educação da UTP. Publicações recentes: A escola de Leonardo: política e educação nos escritos de Gramsci (Brasília: Líber Livro, 2009); Percepção e Conhecimento na aprendizagem infantil a partir de escrito de Benjamin (Educação e Filosofia, v. 24, p. 387-408, 2010); Intelectuais e política: observações acerca do transformismo nos escritos de Antonio Gramsci (Outubro [São Paulo], v. 18, p. 199-220, 2009). E-mail: anita.helenadibero.it 